Supporting Information

\title{
Dissolution of Sessile Microdroplets of Electrolyte and Graphene Oxide Solutions in an Ouzo System
}

Yuting Song ${ }^{1,2}$, Ziyang $\mathrm{Lu}^{3}$, Haijun Yang $^{4}$, Suojiang Zhang ${ }^{2}$, and Xuehua Zhang ${ }^{3}$, Chengdu Institute of Organic Chemistry, Chinese Academy of Sciences, Chengdu, China, Institute of Processing Engineering, Chinese Academy of Sciences, Beijing, China, Soft Matter \& Interfaces Group, School of Engineering, RMIT University, Melbourne, VIC 3001, Australia,

Shanghai Institute of Applied Science, Chinese Academy of Sciences, Shanghai, China E-mail: sjzhang@home.ipe.ac.cn; xuehua.zhang@rmit.edu. 
Figure S1 (a) snapshots of dissolving a typical GO-KCl droplet as a function of time in the $8 \%$ ethanol-toluene solution, scale bar $200 \mu \mathrm{m}$. (b) Diameter square of $\mathrm{KCl}$ and $\mathrm{GO}-\mathrm{KCl}$ solution droplets as a function of time, the initial volume is around $0.25 \mu \mathrm{l}$ and the transit time is $184 \mathrm{~s}$ for pure $\mathrm{KCl}$.
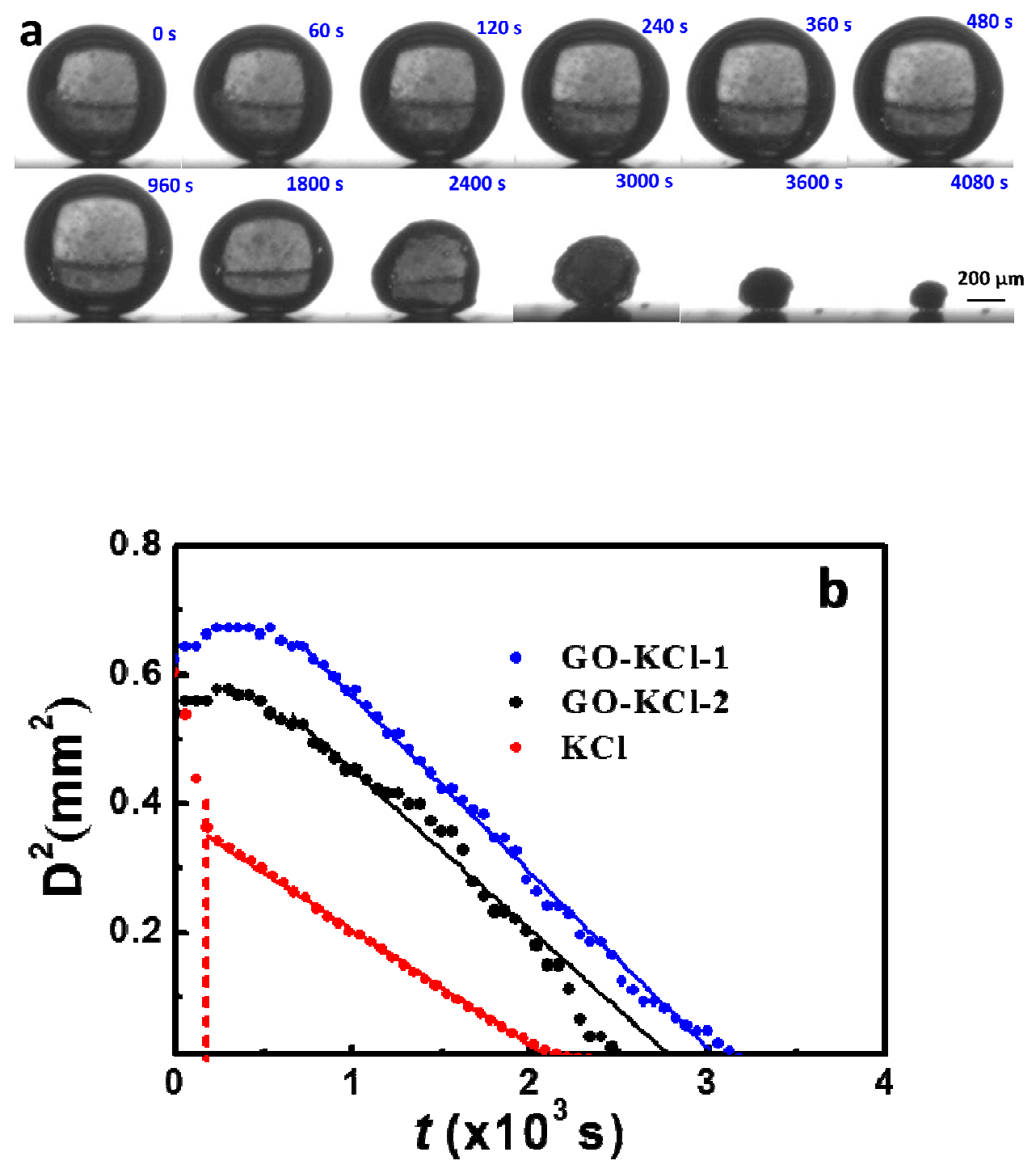
Figure S2 Snapshots of the dissolution of the water droplets in the first stage. The dissolved water from the droplet leads to a rapid outflux down to the substrate, which can be evidenced by the visible waves (red arrows) near the bottom of the droplet due to the refractive index difference. Scale bar is $200 \mu \mathrm{m}$.
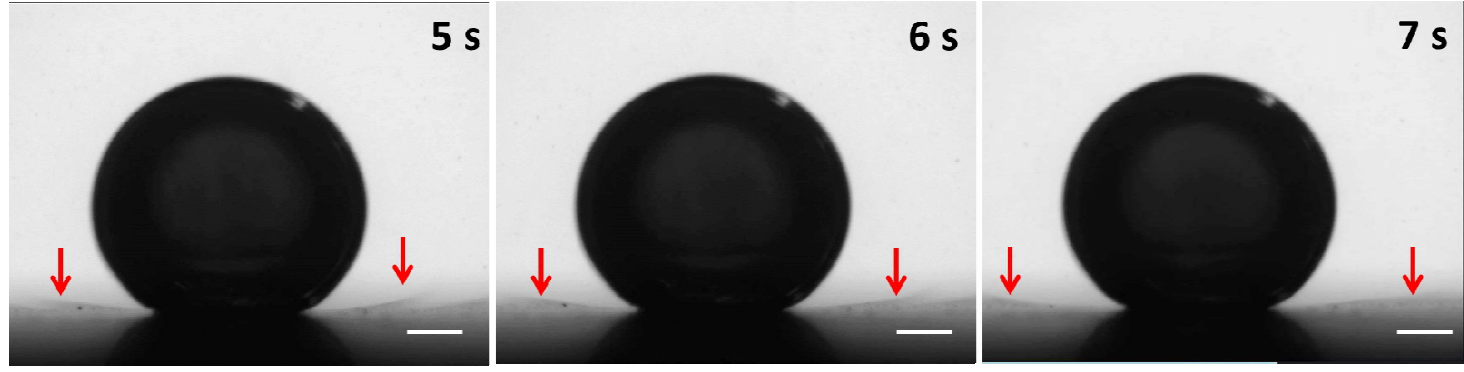
Figure S3 SEM images of dry GO snowballs assembled by the dissolution of a GO-KCl droplet. Both $\mathrm{GO}$ and $\mathrm{LiCl}$ concentration are $0.5 \mathrm{mg} / \mathrm{ml}$.

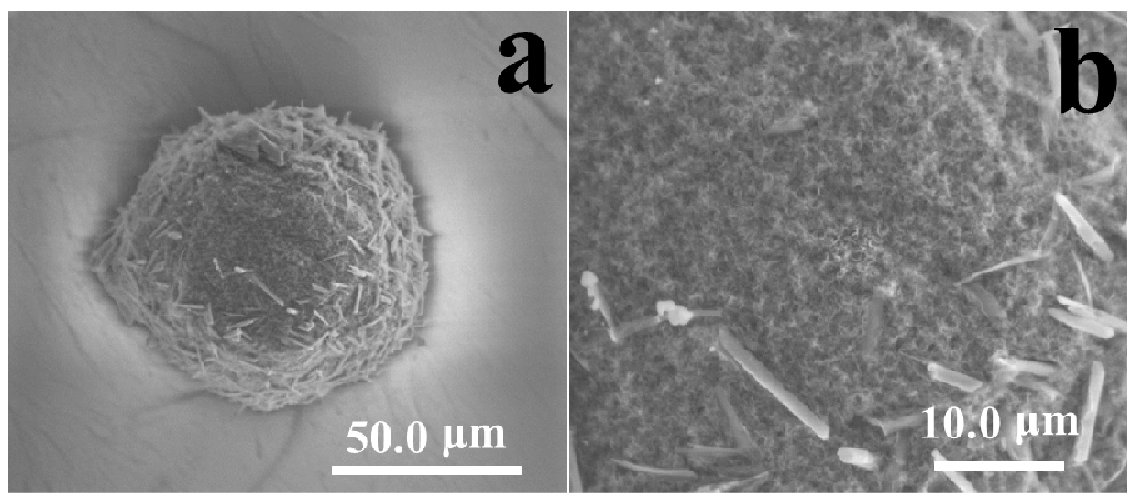

